\title{
A Novel Alerting System for Human Security
}

\author{
Sayli Patil \\ Brahma Valley College of \\ Engg \& Research Institute \\ Nashik, MH, India
}

\author{
Chetan Pawar \\ Brahma Valley College of \\ Engg \& Research Institute \\ Nashik, MH, India
}

\author{
Chetana Jadhav \\ Brahma Valley College of \\ Engg \& Research Institute \\ Nashik, MH, India
}

\author{
Poonam Gangurde \\ Brahma Valley College of Engg \& Research \\ Institute \\ Nashik, MH, India
}

\author{
Kavita S. Kumavat \\ Brahma Valley College of Engg \& Research \\ Institute \\ Nashik, MH, India
}

\begin{abstract}
In today's world, even though there are super power's and an economic development, but still there are many crimes against women. The atrocities against the women can be brought in control with the help of security band. This device is a specially designed for women in trouble. Using Raspberry-pi controller for the hardware device is most efficient and it consumes less power. After going through Google we analysed that there are no security device for safety. The user has to carry multiple devices. A device is found which will increase the safety level. System's used are Raspberry-pi 0 controller and GSM, GPS, Temperature sensor, Heart beat Sensor. The aim of this system is to develop a self defence system especially for women to protect themselves from present day (not physical harassments). The basic approach in this project is to intimate instant location and along with a message to a predefined number like parents, friends, media, and women cell to avoid unfortunate incidents. A single click on this device identifies the location of place through GPS and sends a message comprising this location URL to the registered contacts to help the one in dangerous situations. This would help to reduce the crime against human.
\end{abstract}

\section{Keywords}

Raspberry- pi, Global Positioning System (GPS), SMS Sender, Security, GSM, Temp sensor, heart beat sensor, Security Band

\section{INTRODUCTION}

Even in this era Women are feeling insecure to step out of their house because of increasing crimes in our country like harassment, abuse, violence etc., As corporate and IT sector are currently in boom, many women are working even in night shifts. So there is a feeling of insecurity among these working women

The proposed System will help such working women in case of emergency. This device can be fitted in a band and that can be wore in hand. This device is easy to carry with more features and functions. There are three buttons on this device. The 3 buttons will decide the priority of emergency. The main purpose of this device is to intimate the family, friends, police and doctor about the current location of the women. A GPS system is used to trace the current position of the victim and a GSM module is used to send the message to the pre-defined contacts. There are several applications that reduce the risk of sexual abuse by sending SMS but in our model we also provide temperature and heart beat sensors which is more useful for physically challenged people.
The raspberry - pi 0 acts as an embedded computing system and it controls the activities of all the subsystems. The raspberry pi is interfaced with all the other modules of the device.

1. Raspberry Pi: As shown in figure 1 the Raspberry Pi could be a series of tiny single-board computer developed in the United Kingdom by the Raspberry Pi Foundation to market the teaching of basic applied science. The first model became way more fashionable than anticipated, mercantilism outside its target marketplace for uses like AI.

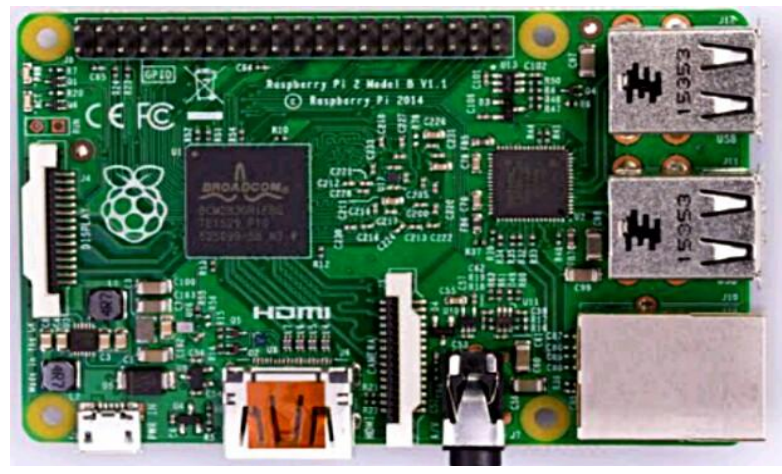

Figure 1: Raspberry pi 0

2. GSM: GSM is a cellular network, which means that cell phones connect to it by searching for cells in the immediate vicinity as in figure 2 .

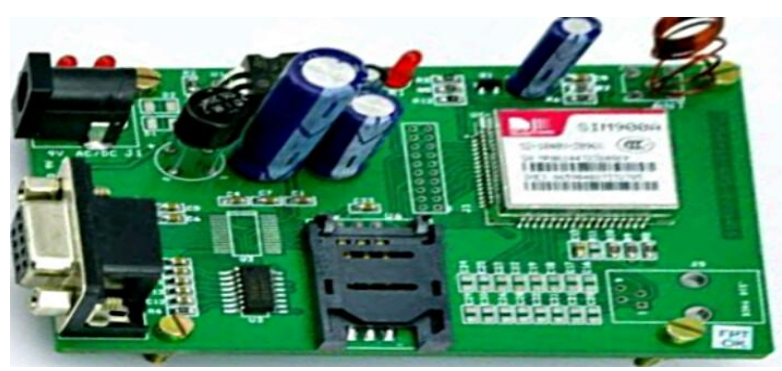

Figure 2: GSM

3. GPS: The Global Positioning System (GPS) shown in figure 3, originally Navstar GPS, could be a satellite-base radio navigation system owned by the United authorities and operated by the United States Air Force. Its a worldwide navigation satellite system that has geolocation and time information to 
a GPS receiver anyplace on or close to the planet wherever there is an unclogged line of sight to four or additional GPS satellites. GPS signals are blocked because of obstacles like buildings blocks and mountains.

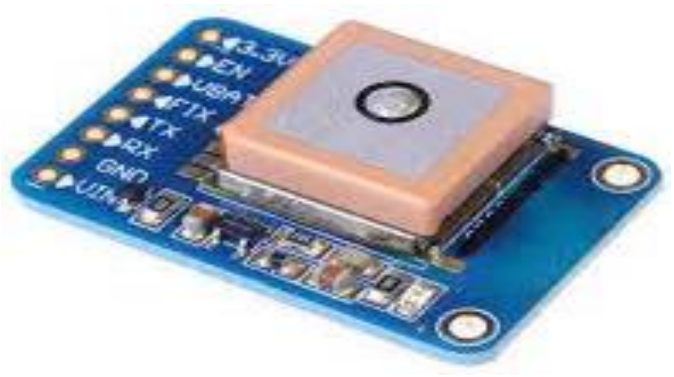

Figure 3: GPS

4. Temperature Sensors: Temperature Sensors in figure 4 measure the amount of heat energy or even coldness that is generated by an object or system, allowing us to "sense" or detect any physical change to that temperature.

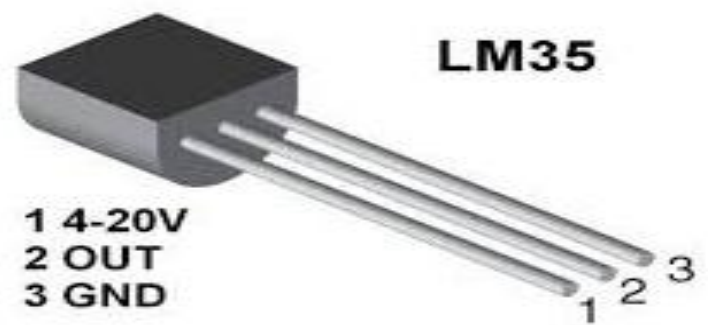

Figure 4: Temperature Sensors

5. Heartbeat sensor: In figure 5 the heartbeat sensor is based on the principle of photo phlethysmography. Change in volume of blood is measured through any organ of the body which causes a change in the light intensity through that organ (a vascular region).
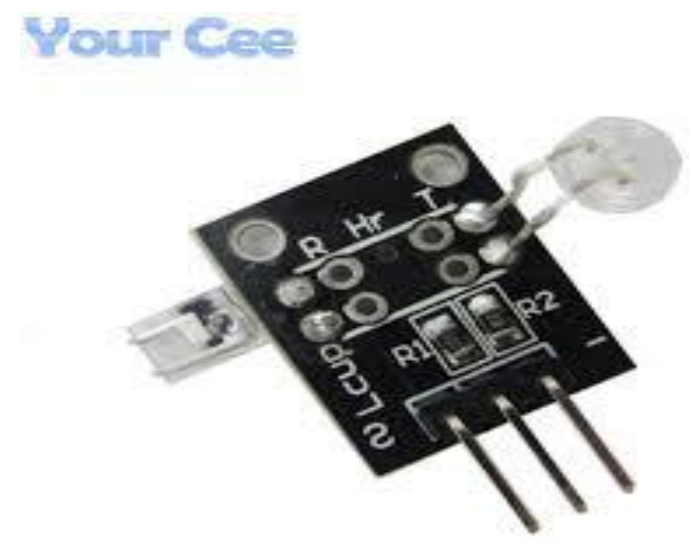

Figure 5: Heartbeat sensor

\section{LITERATURE SURVEY}

In $21^{\text {st }}$ century women are taking hand in hand with men in every field. On previous search we found that there is mobile application for women safety. So now we have searched for devices like band. Actually there are bands available but they are just for fitness purpose.

There already exist few women security applications and devices such as :-

Dr. Sridhar Mandapati, Sravya Pamidi,Sriharitha Ambati [1] prepared for "A MOBILE BASED WOMEN SAFETY APPLICATION." Many incidents have been taking place in woman's case. In 2013 a 23 year old woman was gang raped in a bus in New Delhi at 9:30 PM. In Mumbai another incident took place when woman who left her native place after Christmas holidays was been kidnapped and killed. Here are such incidents that have taken place in day to day life of women these days. To overcome such incidents faced by women the I Safety (women security apps) which is mobile based applications.

Poonam Bhilare, Akshay Mohite, Dhanashri Kamble, Swapnil Makode and Rasika Kahane [2] prepared for Women's safety is the most critical issue in today's world. The following paper describes a "GPS and GSM based vehicle tracking and women employee security system" that provides alerts and messages with an emergency button. The device provides vehicle information which can be viewed on Google maps. As the IT companies are looking forward to the security problem so they require a system that will efficiently evaluate the problem of women employees' security working in night shifts.

Basavaraj Chougula and Archana Naik [3] prepared a "SMART GIRLS SECURITY SYSTEM". This paper suggest a perspective to use technology to guard girls. The system resembles a traditional belt that once activated, tracks the situation of the victim victimization GPS and sends emergency message victimization GSM, to 3 emergency contacts and therefore the police room. The system additionally incorporates a screaming alarm that uses period clock, to decision out for facilitate and additionally generates an electrical shock to injure the wrongdoer for self defense. The advantage of this method is that the user doesn't need a smart phone in contrast to alternative applications that are developed earlier.

Mohammed Ali Mazidi and Janice gillispie mazidi prepared for "The arm microcontroller \& embedded system". This emergency app is initiated by an popular Indian series "GUMRAH" channeled on V channel. In case of emergency we need to press the power button twice of our mobile. After pressing this button our location is send through message in every two minutes to the contacts fed in the app.

M D Singh and K B Khanchandan prepared for "power electronics". This garment is designed by three engineers from Chennai. This garment consists of electric circuit that can generate $3800 \mathrm{kv}$ of current that can help the victim to escape. If there are multiple attacks, it sends approx 82 electric shocks. The fabric is bilayer, so the user is not affected. It can also send emergency messages to the fed contacts.

Pragna B R, et. Al [4] provides an ideology for Women Safety using different devices and applications. They provide efficient mechanism with high performance for safety.

Ms.Sonali S.Kumbhar et. Al. [5] provides a mechanism for Women Security System Using quick response mechniasm using GPS and GSM. When someone is in trouble, she can press the button and the location information is sent as message. It also provide child tracking facility. 
Ramya Sree Yadlapalli et. Al [6] works on women security with "Smart Intelligent Security For Women". System develop wrist band and spectacles with tear gas and pressure switch for daily life.

Sriranjini R et. al [7] works on "GPS and GSM based self defense system." System used microcontroller PIC 16877A for real time response based application for girls.

Ravi kant CEO, Watches and Accessories Division [8] prepared a system for SONATA watch for women safety. The Sonata act watch is integrated with mobile application that can be downloaded on user smarts phone and using Bluetooth. The watch will interface with the mobile to send location and message to the register contacts.

Abhijit Paradkar and Deepak Sharma [9] proposed "ALL IN ONE INTELLIGENT SYSTEM FOR WOMEN SECURITY". a women security mechanism with $100 \%$ safe environment. System also provides gender equality by safe environment. System provide intrusion detection system within home for handicapped person, senior citizen and women. Also it contain security for child using area zone module.

\section{SYSTEM SRCHITECTURE}

Figure 6 show system architecture the device contains 3 buttons. These 3 buttons will decide the priority of emergency i.e. Red Button will have highest priority i.e. in case of sexual harassment or in kidnapped cases etc. Our GPS \& message will be sending through GSM model to Police, family and friends. Green Button will have average priority i.e. in case of any medical emergency i.e. like heart attack, increase in body temperature etc. Our GPS \& message will be send through GSM model to Doctor, Family and Button 3 will have the lowest priority, i.e. like need of petrol, or bike or car puncher etc. Our GPS \& message will be sending through GSM model to Family and friends. The GPS is used to track the location in case of emergency after one of the 3 buttons is pressed. Then the GSM will send the message to the individuals whose numbers are registered in programming. In this way in case of some emergency for i.e. in sexual harassment we can reduce the harm by getting help as earlier as possible. Additional features like temperature sensing and heart beat monitoring are added for physically challenged people.

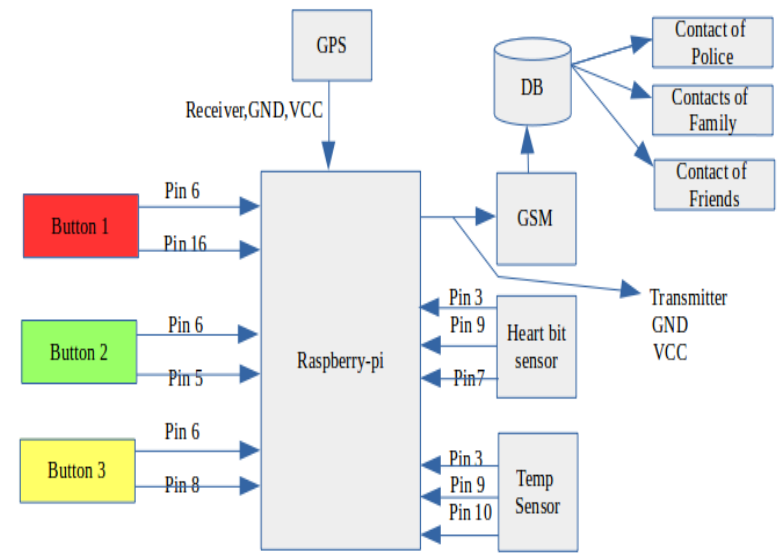

Figure 6: System Architecture

System contain following features:

1. User can add as many phone numbers into our contact list with priority settings.
2. We provide a single click approach to secure them Send message with Location URL

3. Continuous message sender every specific time wireless connectivity.

4. Low cost with high performance.

\section{SYSTEM FLOW}

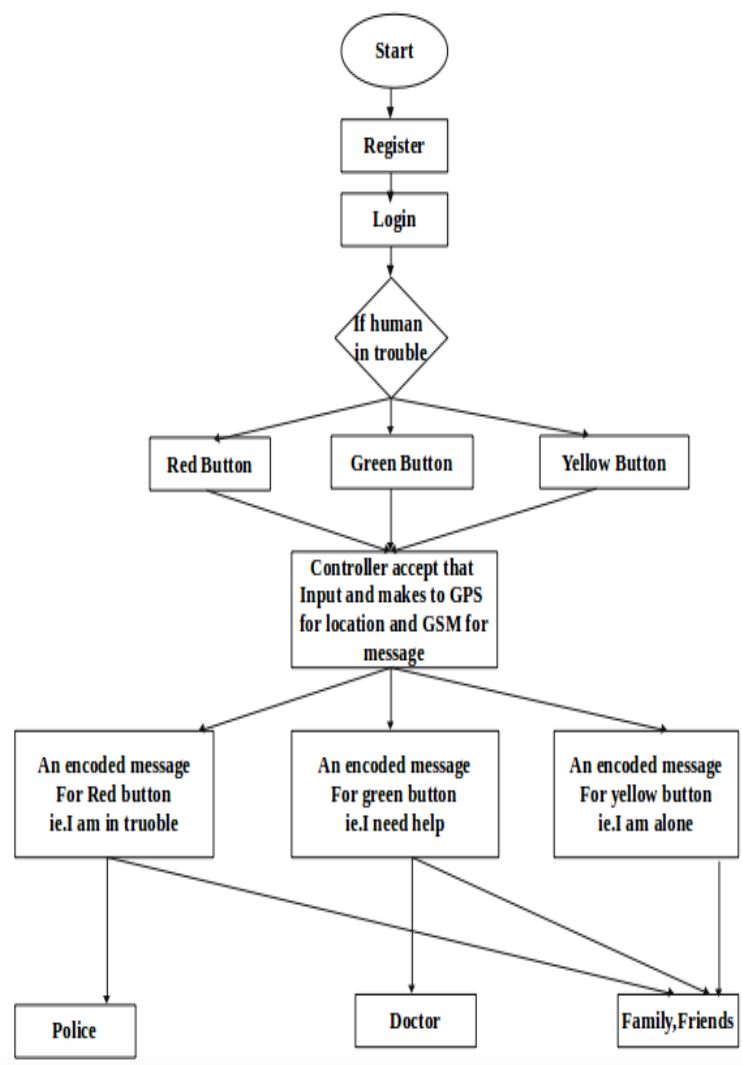

Figure 7: System Flow

Figure :7 show System flow contains all working of system in systematic manner as shown in figure 7. As system is related to human security it contains one band which is easily handle by human at anywhere. That band contains 3 buttons Red, Yellow and Green for different functionality. Red button is used for most care which is connected to the different security aspect like it will notify to police when that particular human is in danger. Yellow is for notifying normal conditions like petrol dement etc. and green button is for medical emergency. After Pressing one of three Button controller accept input and makes GPS for Location and GSM for message and send the Location, message like I am in trouble, I am alone to the Predefine Contacts. The system working is shown as follows-

\section{CONCLUSION}

The wireless machine driven security system for women having some deficiencies that square measure lined by planned system. The society could or might not modification for enhanced; the ability of being actually power sure return from this device. This device can sure give true data as physical device offers guarantee. Our primary goal is that each girls, child, or men in our society ought to stay safe and secured. This method is predicted on the GSM technology and main parts used are Raspberry Pi 0, GPS, temperature sensor, and heart beat sensor. This device are substantially useful to women, whenever they went outside alone. This 
project is for the short term measurement against women for daily harassment as variety of features. System contains different notification buttons for different conditions like Red, Green and Yellow. Also system provides notification for heart beat counting and for temperature sensing. So that proposed system provide a better solution for human security.

\section{REFERENCES}

[1] Dr. Sridhar Mandapati, Sravya Pamidi and Sriharitha Ambati, "A Mobile Based Women Safety Application", IOSR Journal of Computer Engineering (IOSR-JCE) Vol. 17, Issue No. 1, Feb. 2015.

[2] Poonam Bhilare et. al., "Women Employee Security System using GPS And GSM based Vehicle Tracking", International Journal for Research and Emerging Science and Technology (IJREST), Vol. 2, Issue No. 1, Jan. 2015.

[3] Basavaraj Chougula et. al., "Smart Girls Security System", International Journal of Application and Innovation in Engineering and Management (IJAIEM), Vol. 3, Issue No. 4, April 2014.

[4] Pragna B R, et. al "Women Safety Devices and Applications", International Journal of Engineering Research and Technology (IJERT), Vol. 7, Issue No. 7, July 2018.
[5] Ms. Sonali S. Kumbhar et. al., "Women Security System Using GSM and GPS" International Research Journal of Engineering and Technology (IRJET), Vol.5, Issue No.3,March 2018.

[6] Ramya Sree Yadlapalli et. al. "Smart Intelligent Security System For women" International Journal of Electronics and Communication Engineering and Technology(IJECET), Vol. 7, Issue No.2, March-April 2016.

[7] Sriranjini R et. al "GPS and GSM Based Self Defense System For Women Safely" International Journal of Electrical and Electronic System(IJEES),Vol.6 ,Issue No.2,July 2017

[8] Ravi Kant COE Watches and Accessories Division, "SONATA ACT" December 2016

[9] Abhijit Paradkar and Deepak Sharma "All In One Intelligent Safety system for Women Security" International Journal of computer Application,Vol. 130 Issue No.11,Nov 2015

[10] Manav Singhal and Anupam Shukla "Implementation Of Location Based Services In Andriod Using GPS and Web services" International Journal Of Computer Science Issues(IJCSI) ,Vol.9,Issue No.1,JAN 2012 